\title{
Modern Conception of the Mission of Architecture in Architectural Theory and Practice
}

\author{
Eugenijus Staniūnas, Vilnius Gediminas Technical University
}

\begin{abstract}
The article aims to analyse the contemporary conception of mission of architecture. The analysis is done by comparing the conception with principles of rationally organised activity, first of all clarity. The analysis revealed that the description of the mission is unclear and there are logical contradictions between the general definition and elaborated details of it. Two different "philosophies" govern architecture - the theoretically declared one and the one that is used in practice. It was concluded that there is a need for the modernisation of paradigm of architecture.
\end{abstract}

Keywords - Architecture, contemporary, paradigm, problems.

\section{INTRODUCTION}

Historical and cultural anthropology sciences have long been examining the relationship between the world-outlook and life practice of various cultures. Yet, I dare say, this topic has recently been discovered anew in a particular way. I would like to refer to Thomas S. Kuhn's book "The Structure of Scientific Revolutions", which attracted a lot of attention, wherein he investigates the evolution of science and argues that scientific research and thought are defined by "paradigms" or conceptual world-views that consist of formal theories, classic experiments, and trusted methods [1]. The influence of fundamental provisions onscientific research, primarily physics and chemistry, was discussed in a number of books written by I. Prigogine, E. Stengers and others [2], [3], [4]. I. Prigogine's and E. Stengers' books arrest reader's attention in a sense that they include not only the world-views of the past and seem to be no longer relevant but also the fundamental concepts which not long ago controlled or even continued to control physics, chemistry and other sciences. Therefore, the world of concepts which have an impact on human life attracts the attention of researchers working in various scientific areas.

In this context, the research on the culture of architecture appears to be rather simple: the thoughts, especially contemporary ones, on which the mode of architectural activity is based, are still little examined. In this paper, I would like to share my observations concerning the logic of essential thoughts that are "constructing" the way of forming an architectural environment - in other words, the main elements of content of the contemporary paradigm of architecture.

Where do these thoughts (concepts) exist? - In everything that we do in architecture. They are declared in theoretical works, found in the trends of architectural research, embodied in activity programs, materialized in architectural practice.

Before I start discussing the features of the paradigm of contemporary architecture, I would like to explainwhy I find it important and how the logic of architectural life can be investigated.
Profound knowledge about the fundamentals of contemporary architecture not only expands our intellectual horizon in general; the study of the paradigm, by which we are controlled during our life, has a very practical meaning. The paradigms age like many things. The aim of this research is to review the present-day fundamentals of architectural activity in order to observe the moment when the above-mentioned "friction" appears between the fundamentals) and the accumulated knowledge of architecture. It is important not to allow the fundamentals exist without being practically applied or, even worse, become an obstacle.

This historic experience "prompts" the main methodological principle of revising the paradigm. We can see whether or not it is still relevant by comparing it with knowledge about architecture (and not only) which has been accumulated up to the present days. If the accumulated knowledge tells us one thing and the paradigm "forces" us to do another, it will mean that the moment has come when it is required to modernize the fundamentals of architectural life.

This article will analyse three issues. At first, I will overview the present-day definition of the mission of architecture and discuss what "construction" this definition attributes to architectural life. The task of this overview is to make the most important elements of the paradigm more visible. Then, I would like to look at the details of defining the mission of architecture and compare these details with the general concept of the architectural mission (I will search for the mistakes of logic inside "philosophy" of architecture). Finally, I will compare the declared explanation of the architectural mission with the concepts embodied in architectural practice (I will search for the differences and contradictions between the theoretically declared and practically working "philosophies" of architecture.

\section{A. The Description of the Mission of Architecture and Pecu- liarities of the "Construction" of Living Dictated by it}

The logical foundation of the activities of any non-spontaneously operating organization is a set of fundamental provisions (this foundation dictates the essential features of "constructing" those activities): the conception of the place of those activities in life (their mission), the vision of the desired results and the notion of aims consequent upon these results. What is that set of thoughts like today - in other words, what is the logical foundation that we use to build our architectural life?

Let us start from our thoughts recorded in the most respectable documents, providing public with an explanation of the meaning of architecture and its tasks and place in social life - encyclopaedias, dictionaries, the statements of architects' organizations, 
government programs, and other respectable sources of public information.

Probably, most often the texts describing the role of architecture say that the mission of architecture is "to meet human needs". For instance, the UNESCO/UIA Charter for Architectural Education in many places uses these or other expressions the meaning of which is very similar. For example, when presenting general considerations, it says:" ... it is in the public interest to ensure that architects are able to understand regional characteristics and to give practical expression to the needs, expectations and improvement to the quality of life of individuals, social groups, communities and human settlements" [5, 4]. When describing the objectives of architectural education, it says that an architect must have "understanding... of the need to relate buildings and the spaces between them to human needs" $[5,6]$.Presented at the UIA Congress, the Warsaw Declaration of Architects states “... architects and planners should assume responsibility for meeting these needs in the process of shaping every environment" [6]. We can find many more similar statements in other texts dedicated to architecture. I do not cavil about the words "human needs"-it can be similar ones, like"expectations", "ends" and others. I do not think, that the span of the list of these needs is very important, because they are the most broad-brush (most generalised) definition of mission of architecture. The popularity of them shows the popularity of such understanding.

Nowadays, we elaborate on the definition of architectural mission stating (most often) that human needs which architecture must meet are practical and aesthetic. The definition of architecture provided in Encyclopaedia Britannica can serve as an example of such statement. It says that architecture is the art and technique of designing and building... fulfilling both practical and expressive requirements, and thus it serves both utilitarian and aesthetic ends [7].

The very thought that the mission of architecture is to "meet human needs" points to the crucial elements of the "scenario" of contemporary architectural life.

Most importantly, there are "players". According to the description of the mission, there are two of them: human being and architectural environment.

The conception of the mission fulfils one more function which deals with distributing the roles (duties) of the "players". The role of measurement is attributed to human being, while the architectural environment performs the role of being measured and altered. The role of measuring is simply to exist. The role the environment carries out is to be analysed, measured, created and modified.

The conception of the mission specifies the process which has to happen as well. This process, as the mission's formulae goes, consists of two parts: 1) transformation of environment (from not satisfying human needs to satisfying them); 2) transformation of feelings of people (from discomfort to complacence).

This understanding of the mission focuses the whole attention of architecture community on the environment.
B. Peculiarities of the Declared Definition of Mission of Architecture. General and Elaborated Definition of it

The mentioned description of architectural mission, which claims that the purpose of architecture is to meet human needs, is very broad.

1) In modern texts dedicated to architecture there is no detailed definition: "What does one understands by the word "human"? The phrase "human needs" can be perceived differently: as personal needs, as needs of human society (which sometimes can differ from individual needs), as a generalization of human needs, and maybe even as something else. We say that the purpose of architecture is "to meet human needs"; however, we do not comment on the word "human". Does it mean that by referring to this description of architectural mission we want to say that it makes no difference how we understand the expression "human" needs? It is true that recently more encouragement given to architects to interact with local people can be found in software architecture documents [5,6]. It slightly narrows the expression "human needs"; instead, we could say "meeting the needs of local people", but the meaning of even this expression still remains rather broad.

2) There is one more point to be taken into account: What does the verb "to meet" means? Does it imply that "to meet" is to protect the present-day lingering harmony between human and his/ her environment? Does it mean that at present it (harmony) does not satisfy those needs yet (or does not satisfy them completely), and "to meet" indicates a better satisfaction of those needs? Does it mean that every construction being built has to meet human needs at present and remains as such throughout centuries, or "to meet" implies something else? I cannot find answers to these and similar questions in contemporary literature.

3) The architecture-related texts speak vaguely of whose needs architecture must satisfy. Architectural critic Ada Louise Huxtable calls architecture a "balance of structural science and aesthetic expression for the satisfaction of needs that go far beyond the utilitarian" [8]. Still some texts explaining the mission of architecture do not speak very much about any balance: they stress the artistic role of architecture. Larousse Encyclopaedia defines architecture as the art of construction [9]. Some software documents presenting the policy of professional activity leave the impression that their authors agree that architecture meets different needs, and still think that not all of these needs are equally "architectural". For instance, one of the tasks set for architects in Policy Statements prepared by the General Assembly of the Architects' Council of Europe says: "Ensure that the procedures used for the procurement of buildings and all structures that constitute the built environment,..., are conceived and implemented in such a way that they permit the selection of the best quality proposals having regard to sustainability, architectural quality and life cycle costing" [10]. Since "sustainability", "architectural quality" and "life cycle costing" are named separately, it means that they are treated as different phenomena. We can draw various conclusions among which there is one that we must concern ourselves about "architectural quality" in architectural activity first and only then take care of other non-architectural(?) "qualities". 
4) In contemporary texts, which explain the mission of architecture, there are other aspects exacerbating our understanding of what architecture should do. It is not clear not only whose needs and what needs one must satisfy: today, it is also not clear what those needs are, especially when taking into consideration "aesthetic needs".

Having declared that the mission of architecture is "to serve both utilitarian and aesthetic ends", encyclopaedias and dictionaries take an important step forward explaining what these "utilitarian and aesthetic ends" are. This is how that elaboration of architectural tasks looks like.

The Encyclopaedia Britannica says that there is no definite and concrete answer what aesthetics is: "To provide more than a general definition of the subject matter of aesthetics is immensely difficult" [11]. Hence a significant part of the declared architectural tasks appears to be undefined by the Encyclopaedia.

Maybe it is possible to understand what this side of the architectural mission is while explaining the meaning of the word "art"?

The Encyclopaedia Britannica provides the following definition of "art": "Art is treated in a number of articles. For general discussions of the foundations, principles, practice, and character of art, see aesthetics" [12]. Those who want to find out what art is, the Britannica directs you to the definition of aesthetics in which we, as we know, will not learn anything more. Other encyclopaedias speak in a similar way. For instance, in the Visual Arts Encyclopaedia it is written "...a simple definition, or even a broad consensus as to what can be labelled art, is likely to prove highly elusive" [13].

Similar, sometimes even "more desperate", explanations can be found in a number of prestigious publications. The Russian Dictionary of Philosophy strongly states that it is not even possible to do so, saying: "The peculiarity of interpreting works of art exists in the fact that the meaning being inherent in these works is untranslatable into the language of concepts and remains ineffable by any other means until the end" [14]. Thus, it is impossible to ascertain the content of a work of art by any means. If one is, by any means, incapable of finding out what architectural works of art "speak of", then, in my opinion, it is impossible to determine as to whether they "speak" at all.

A significant statement follows: "None of answers to an eternal and complicated question: "Why does man need art?" cannot be complete and absolute" [14]. Applying this statement to architecture, we can say that "not a single answer to the question: 'Why is man in need of the art of architecture?' can be universal and ultimate."

If one integral part of the mission is not clear, neither is the whole mission.

All the mentioned facts lead me to the conclusion that the contemporary description of the mission of architecture is not very logical.

Similarly look the problems of explanations of mission of architecture. The panorama of its concept becomes more complicated if one considers architectural practice.
C. The Declared Concept of the Mission and the Concept Embodied in the Practice of Architecture

The logical system could not act if it did not know what it should do. The architectural society acts, the architectural life is "boiling". It means two things: 1) architectural praxis (as opposed to theory) knows what to do and 2) this knowledge is (at least slightly) different from the theoretical one described above. Let us look at it and try to understand the considerations governing it and compare them with the theoretical (declared) ones. In other words - let us try to analyse, how the declaration "to meet human needs" is seen from the practitioners point of view - from its perspective.

Probably different methods can be used for such analysis. I would like here to examine the peculiarities of the practical activity. The mode of activity is not a casual thing: each mode of activity (each form of it) is organized according to someone's mind - someone's understanding of architecture. I have looked at the practical life of architecture and tried to understand what concept of architecture stands behind it.

The contemporary culture of architectural practice has many specific features. Let us remember some of them. For example, these days, architects and non-architects evaluate the suitability of architectural works in a categorical way. These are not individual exceptional cases but occasional instances of contemporary architectural life. No one opposes such (categorical) evaluation.

There is another typical peculiarity of the contemporary practical life. Those who participate in today's architectural life not only indicate which kind of architecture "meets human needs", but also argue its suitability. It is logical to argue something which exists only objectively - regardless of those who want to argue. To prove what you just feel would not make any sense - it would have to be said. Hence, trying to argue the suitability of architecture shows that the present-day participants in architectural life stick to the opinion that there do not exist clear or even objective criteria for assessing the suitability of architecture for humans.

It would be very illogical to evaluate architecture's suitability if we thought that we do not know its destination (its mission). Referring to the peculiarities of the practice of architecture, we can draw the conclusion that human needs are assumed as wellknown for those who take part in modern architectural practice.

It is acknowledged that the formation of the environment should be undertaken by specialists - architects. If there was something unclear here, then we would not form a group of specialists who would implement unclear tasks. To appoint specialists to undertake architectural tasks (keeping in mind that these tasks are not clear) would indicate a complete misunderstanding.

At present we select the best works of architecture and reward the best architects. It would be illogical to act so if we thought that we do not know what these works are praised for and what valuable contributions their authors have made.

All of the afore-mentioned and similar facts demonstrate that architectural life in practice is governed by the following concept: the practitioners know human needs. In other words, the peculiarities of the contemporary culture of architectural practice show, that from the viewpoint of traditional practitioner "human 
needs" are the needs the individual has in mind. With that in mind we can easily put forward the task of enhancing the quality of architecture - meeting human needs is even better.

What kind of relationship exists between the concept of mission of architecture in theory and concept of mission in practice? Those who act in practical architectural life (differently from theorists) cannot afford the luxury to leave questions unanswered. They simply have no other way but to provide problematic areas with concrete and unambiguous answers. The participants of practical architectural life "adopt" the thoughts included in the declarations in a creative way. 1) They "connive" at theoretical reasoning which seems to be uncomfortable for the practice of architecture. 2) They provide their own answers for those areas of the theoretical concept of the architectural mission which theory leaves open for interpretation. In the result of such equilibristic logic the value of any architectural object becomes obvious and the question of what to do with this object becomes completely clear.

If it seems "absolutely apparent" which architectural works are beautiful and which are not, the importance of specific explanations concerning the essence of the needs architecture must meet, slacks: why do we need to waste our time explaining something which already "pokes the eyes"? The Visual Arts Encyclopaedia poses a question: "If we appreciate its positive impact, do we need to define Art?" [7]. The questions: "What are human needs?" "What is art?" in our today's life are apparently drowned in the question of "what architecture is beautiful?" In this situation, the issue related to the future of the relationship between humans and the environment somehow loses its topicality. We obviously see which environmental organisation is suitable for us and which is not, thus the desired future is clear: it is "good" architecture and nothing more.

\section{Conclusion}

Concluding the article I would like to return to the issue raised in the beginning, that is, to "analyse" the contemporary thoughts, constructing the mode of architectural activity (its paradigm). The coexistence of two ways of thinking is the significant peculiarity of it - the thinking in theory and thinking in practice. Both of them have specific intrinsic logical weaknesses and in addition they logically do not fit one another. The theory lacks clear description of the mission of architecture. The formulation of the mission logically contradicts the level of its elaboration: it is not correct to set an unclear task for any activity. Architectural practice is governed by the thought that "human needs" are the needs each concrete practitioner has in his mind. Only self-jugglery creates the image of the harmony between the theory and practice of architecture. All of it together contradicts today's accepted principles of rationally organised activity of any organization.

These findings lead to the conclusion that the moment of the necessity to modernise the contemporary paradigm of architecture has come. Of course, other tests of the paradigm are welcome.

\section{REFERENCES}

1. Kuhn, T. S. The Structure of Scientific Revolutions. Chicago: University of Chicago Press, 1962. 264 p.

2. Prigogine, I., Stengers, E. Order out of Chaos : Mans New Dialogue with Nature. New York: Bantam New Age Books, 1984. 432 p.

3. Prigogine, I., Stengers, E. The End of certainty. Time chaos and the new laws of nature. London: The Free Press Edition, 1997. 234 p.

4. Prigogine, I. Is the future given? Singapore: World Scientific Publishing Co.Pte.Ltd., 2003. 145 p. https://doi.org/10.1142/5352

5. Charter UNESCO/UIA for Architectural Education [cited 01.09.2015]. http://www.uia.archi/sites/default/files/charte-en.pdf

6. The Warsaw Declaration [online]. ARC Peace [cited 01.09.2015]. http:// www.arcpeace.org/en/publications/item/158-the-warsaw-declaration

7. Ackerman, J. S. Architecture [online]. Encyclopaedia Britannica [cited 01.09.2015]. http://www.britannica.com/EBchecked/topic/32876/architecture

8. Huxtable, A. L. Inventing American reality [online]. The New York review of Books, Vol. 39, Nr. 20, December 3, 1992 [cited 01.09.2015]. http://www. nybooks.com/articles/1992/12/03/inventing-american-reality/

9. Architecture [online]. Larousse [cited 25.08.2015]. http://www.larousse. fr/encyclopedie/divers/architecture/22679\#915950

10. ACE Policy Statements : Elections 2009 [online]. Architects' Council of Europe [cited 25.08.2015]. http://www.ace-cae.eu/public/contents/getdocument/content id/43

11. Scruton, R. Aesthetics [online]. Encyclopaedia Britannica [cited 02.09.2015]. http://www.britannica.com/topic/aesthetics

12. Art [online]. Encyclopaedia Britannica [cited 02.09.2015]. http://www. britannica.com/art/visual-arts

13. Definition of Art [online]. Visual Arts Encyclopaedia [cited 02.09.2015]. http://www.visual-arts-cork.com/art-definition.htm\#need

14. Искусство [online]. Философская энцииклопедия [cited 02.09.2015]. http://dic.academic.ru/dic.nsf/enc

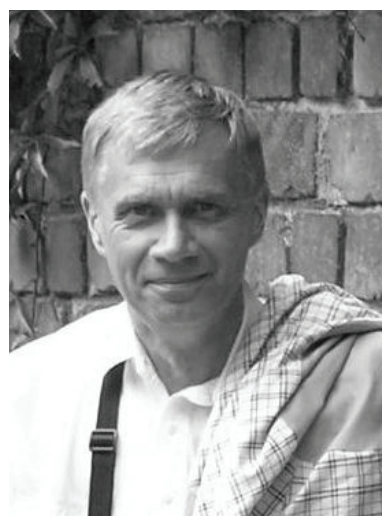

Eugenijus Kęstutis Staniūnas graduated from Vilnius Civil Engineering Institute (presently Vilnius Gediminas Technical University) in 1974. He defended the doctoral dissertation in Moscow Institute of Architecture in 1993. Until 2015, he lectured on Fundamentals of Town Planning and Urban Sociology, Urban Planning Theory and Methodology, History of Urbanistics. He runs practical classes in urban planning and urban design.

Currently he is a Professor with the Department of Urban Design of the Faculty of Architecture of Vilnius Gediminas Technical University (Lithuania). He has also worked at Vytautas Magnus University in Kaunas (Lithuania), and as an architect in Municipal enterprise "Vilniaus planas".

His main areas of interest are culture of architecture and urban planning. His recent publications are:

- Staniūnas, M., Staniūnas, E., Burinskienè, M. Application of indices for assessing the ecological potential of urban development. Ekologija. 2010. Vol. 56. No. 3-4. pp. 79-86. Lietuvos mokslų akademijos leidykla, 2010. ISSN 0235-7224.

- Staniūnas, E. Remarks on the Features of Lithuanian Planning Culture (p. 139-151) - co-author in monograph "Planning Cultures in Europe" Edited by J. Knieling and F. Othengrafen. Ashgate Publishing Limite. Farnham, England. 2009. ISBN 978-0-7546-5.

- Staniūnas, E. (together with co-authors). Planning urban systems in Soviet times and in the era of transition: the case of Estonia, Latvia and Lithuania. Geographia Polonica 2002. Vol. 75, No 2.pp. 75-1001. 


\section{Contact Data}

\section{Eugenijus Kęstutis Staniūnas}

Vilnius Gediminas Technical University

Faculty of Architecture

Department of Urban Design

Address: 26/1 Pylimo St., Vilnius, LT-01132, Lithuania

E-mail: e.staniunas@gmail.com 